\title{
Application of GeoGebra software into teaching mechanical engineering courses
}

\author{
Diyan M. Dimitrov ${ }^{1, *}$ and Stoyan D. Slavov ${ }^{2}$ \\ ${ }^{1}$ Technical University of Varna, Department of Mechanics and Machine Elements, 9010 Varna, \\ Bulgaria \\ ${ }^{2}$ Technical University of Varna, Department of Manufacturing Technologies and Machine Tools \\ 9010 Varna, Bulgaria
}

\begin{abstract}
Mechanics courses traditionally characterize with a rather low percentage of passing students. Dynamic mathematical packages like GeoGebra are widely used nowadays for teaching mathematics, but its interactive capabilities can be used for simulation of different physical phenomena. In this article few interactive applets for Static, Dynamic, Strength of Materials and Theory of Mechanisms and Machines courses, are presented. An experiment with comparison of the test results of two group of students after the exercise beam about internal forces, shows that group trained with GeoGebra applets have significantly higher mean result.
\end{abstract}

\section{Introduction}

Mechanics courses are fundamental for all the curriculums' in mechanical and civil engineering. Traditionally, they are characterised with rather low percentage of passing students, because for effective learning of main concepts in mechanics a good understanding of calculus is needed, as famous quote of Leonardo da Vinci says: "Mechanics is the paradise of the mathematical sciences because by means of it one comes to the fruits of mathematics".

On the other hand, with rapidly changing technologies nowadays, 4 or even 3 years bachelor's degree curriculum can't afford to give enough classes for fundamental courses. That's why teachers have to enhance teaching effectiveness, by preparing electronic course materials and other web based resources.

GeoGebra is a dynamic calculator which connects algebra, geometry and calculus. The software is open source, freely available for all the platforms (www.geogebra.org ) and translated to more than 50 languages [1,2]. The main purpose of the software is to help mathematical teachers to visualisation mathematical ideas from primary school to university [2-4]. There is strong GeoGebra community and a network of International GeoGebra Institutes which seeks to support events and efforts related to open educational materials, teacher education and professional development [5, 6]. Many projects for Math's teachers and students future math teachers realised in different countries reports good results. [7, 8].

The interactive simulations created with GeoGebra can be used not only in math education but also in mechanic courses. For example, authors from Spain reports that

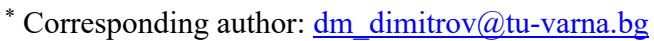


interactive simulations used in teaching fluid static course, helps the students in their selflearning [9]. Similar study in the field of vector mechanics is shown in [10]. In [11] another set of interactive simulations connected with topics for area properties (centroid and area moment of inertia), as well as stress transformation by preparing interactive Mohr's circle, and theirs impact on students is shown.

The aim of this paper is to present how concepts of dynamic geometry are applied in mechanics courses in the Technical University of Varna, Bulgaria.

\section{Case studies}

Some interactive simulations, prepared on GeoGebra software, used in lecture and seminary classes, are shown below. The applications cover topics from Static, Strength of materials and Theory of Mechanisms and Machines courses.

\subsection{Strength of materials}

Conception for internal forces is one of the main chapters of this course. On Figure 1 the bending moment diagram of simply supported beam with point load is shown. By using dynamic slider, loading force can be moved along the length of the beam. The values and the size of support reactions updates dynamically. Bending moment diagram is drawn and maximum bending moment value can be explored. Additionally tracing points of maximum bending moment are visible.
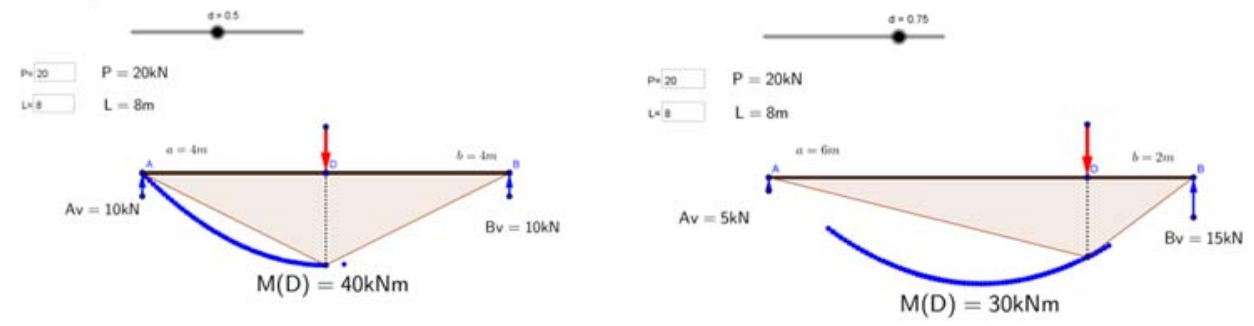

Fig. 1 Bending moment diagram and reactions of the supports in simply supported beam with point load.

The next application presents internal forces in two bar truss construction. By moving the supports (points A and B) up and down the values of internal forces updates dynamically. On Figure 2 different position of the supports is shown.

Strain energy approach is powerful tool for solving displacements and rotations in elastic constructions and impact problems. On Figure 3 the problem of solving vertical displacement of point " $\mathrm{C}$ " of two bar truss is presented. In this application checkboxes are used to present solution of the problem step by step. The deformed shape of the members is shown with dotted lines. Next example (fgi.4) shows the solution of the following impact problem taken from [12]. The ice block with mass $\boldsymbol{m}_{0}=\mathbf{2 5 0} \mathbf{k g}$ swimming with velocity $V=\mathbf{1 , 5} \mathbf{m} / \mathbf{s}$, hits the periscope of the submarine. The length of the periscope is $\boldsymbol{L}=\mathbf{5} \boldsymbol{m}$ and the dimensions of the tube section are $D=35 \mathrm{~cm}, \mathrm{~d}=\mathbf{2 4} \mathbf{c m}$. Find the maximum displacement at the tip and maximum stress in the base of the periscope tube? 

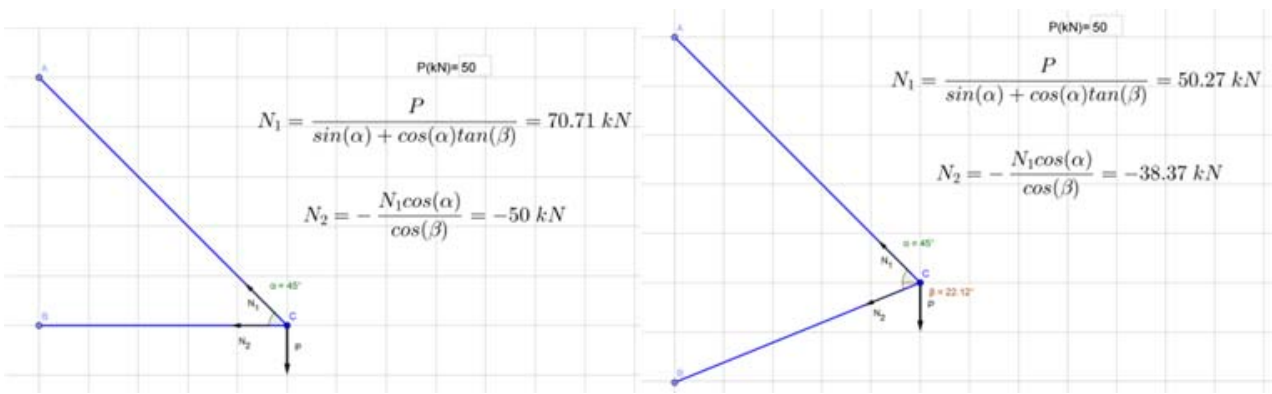

Fig. 2 Internal forces in two bar truss construction.

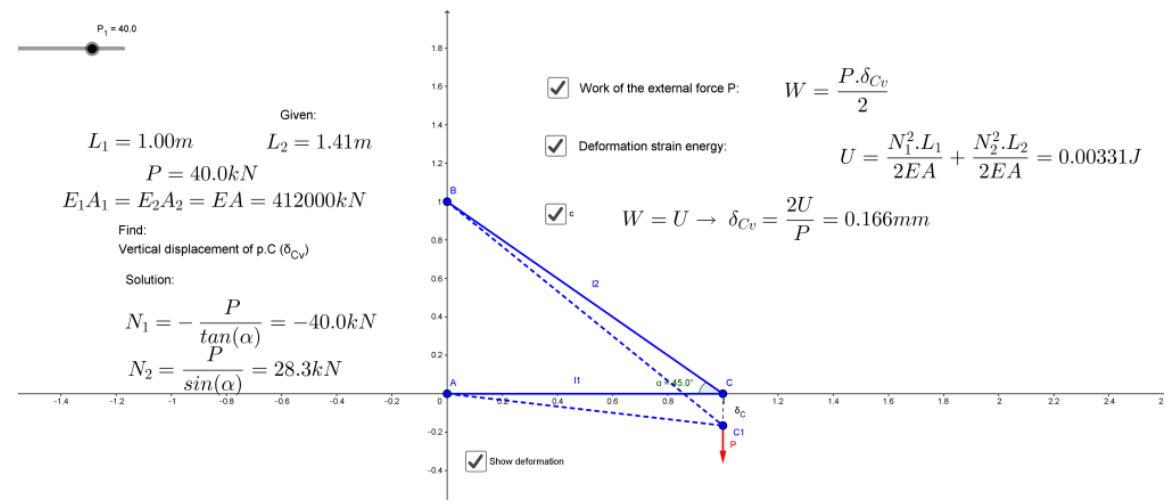

Fig. 3 Work energy approach for solving vertical displacement of point "C".

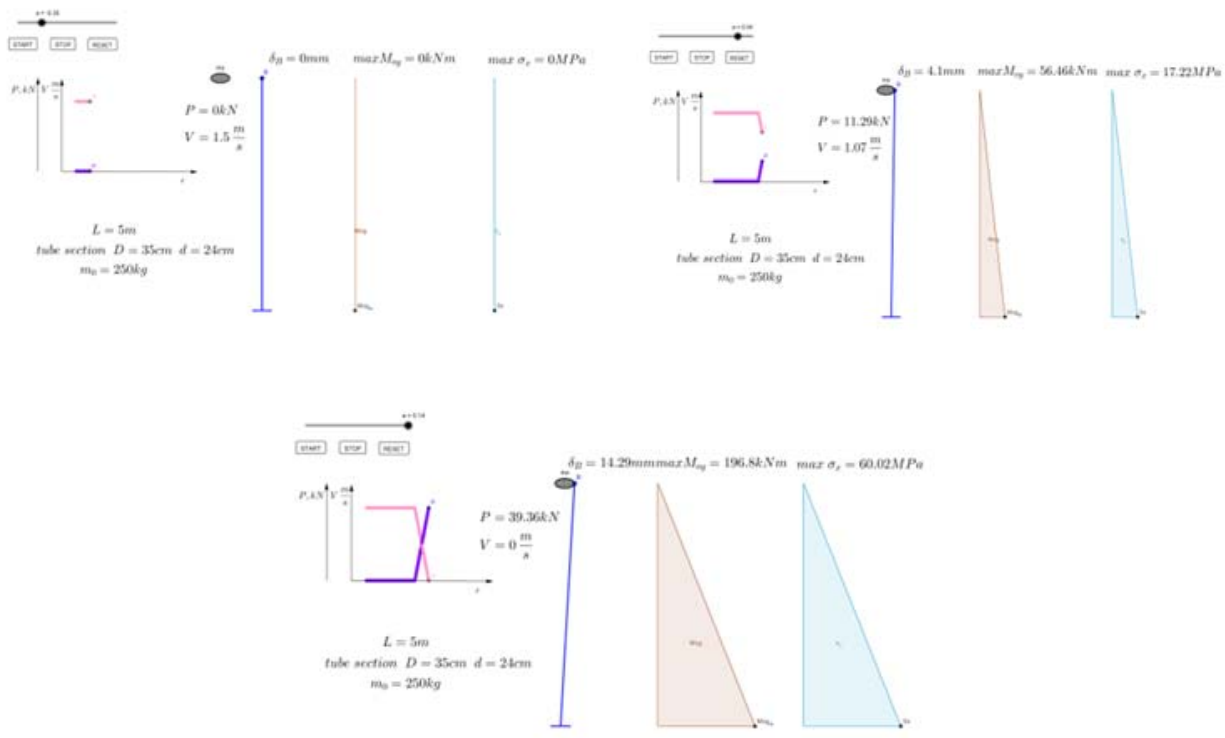

Fig. 4 Ice block hits the periscope tube of the submarine. Velocity of the ice block, impact force, bending moment and normal stress in the periscope.

To find the solution of the problem one have to equalise the kinetic energy of the ice block with a work of the equivalent dynamic force (by Clapeiron's theorem) and strain energy in the periscope tube expressed with bending moment. The periscope tube is modelled as the 
cantilever beam. The dynamic application shown on Figure 4 is constructed using simple scripts to add "Start", "Stop" and "Reset" buttons. Three positions of the ice block are shown (Figure 4): before the impact, during the impact where the velocity of the ice decrease and equivalent dynamic force increase and the maximum impact position where the velocity of ice is zero and all the of its kinetic energy is transformed to beam strain energy.

Another suitable topic for dynamic approach is eccentric axial loading. Here the kind of stresses in the section depends on position of application point of the axial load. So the neutral line (zero stress line) can pass through the section (dividing the section to tension and compression regions) or if the load is in such called "core" of the section the neutral line is outside the section. By dragging the point "P" in the application presented on Figure 5 students can see the position of the neutral line. By dragging the point " $S$ " the value of the stress in any location can be checked.

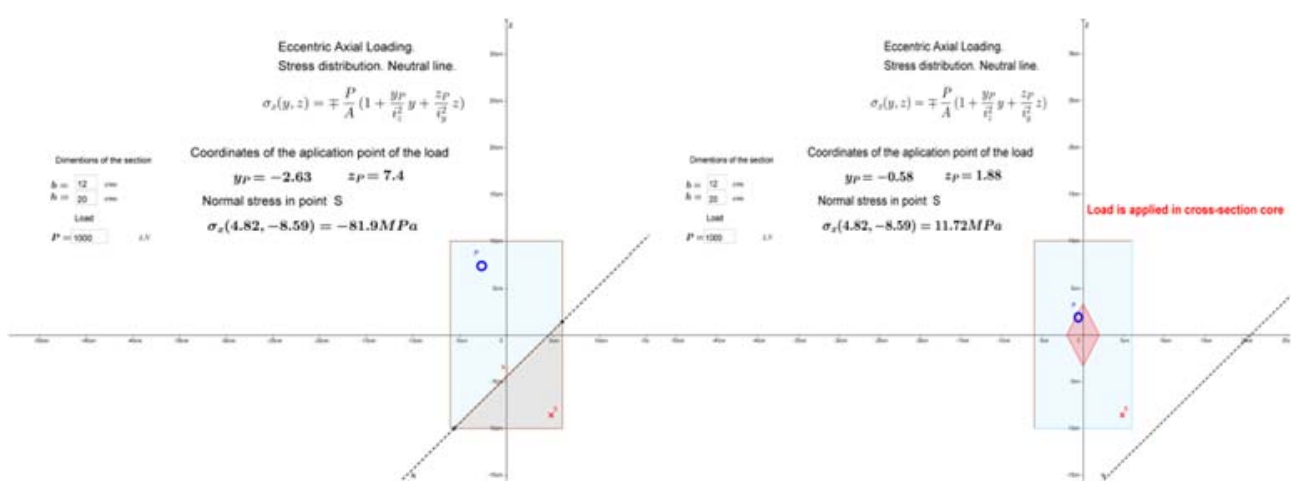

Fig. 5 Eccentric axial loading. Core of the section.

\subsection{Theory of mechanisms and machines}

The benefits of GeoGebra are probably most significant in Mechanisms and Machine Theory course, where the description of mechanisms is not easy to represent with static drawings $[13,14]$. Tracing point option can be used to present trajectory of the moving points. The tools for easily creating parallel and perpendicular lines are perfect for construction of the velocity and acceleration plans which updates with a moving of the mechanism. On Figure 6 and Figure 7 two simple mechanisms are shown. Four bar linkage with a trajectory of point "E" and velocity plan and classical crankshaft mechanism with velocity and acceleration plan of the piston.

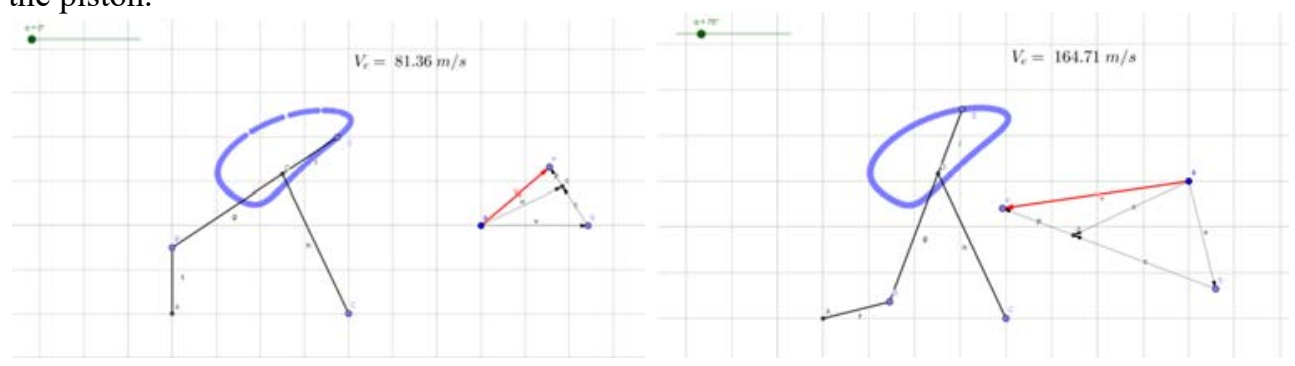

Fig. 6 Four bar linkage mechanism. Velocity plan and trajectory of point «E ». 


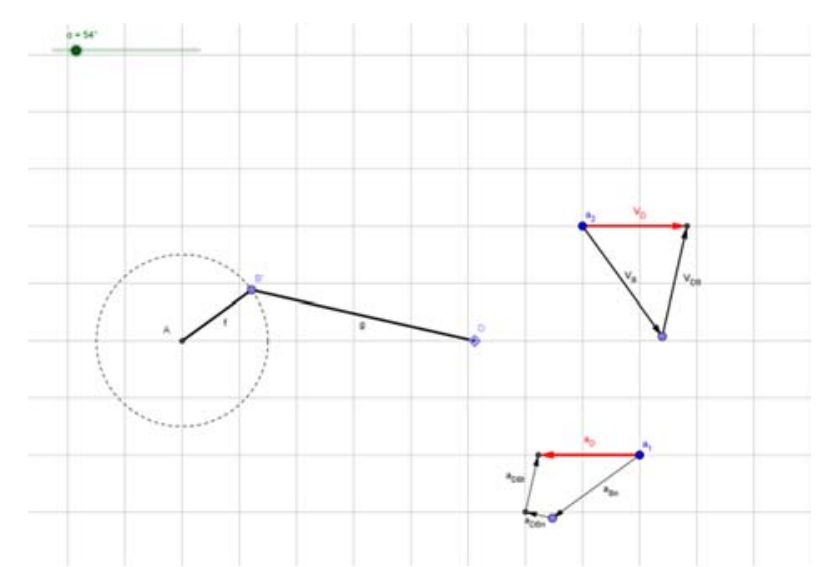

Fig. 7 Crankshaft mechanism. Velosity and acceleration plan of the piston.

\section{Test of the effect of the GeoGebra applets}

The last three academic years the GeoGebra dynamic applets have been used mainly in lecture classes. Students find them useful and attractive, as it can be seen from post semester questionnaires, but overall exam results are not improved significantly. From 2017/18 academic year we begin to incorporate dynamic applets in the seminary and laboratory classes. Students works in the computer room where they can explore themselves the applets and discuss with their colleagues and the teacher. To evaluate the benefits of such classes to students the post test results of two group of 15 students each, are compared. The chosen topic is internal forces in beams and especially three and four-point bending. In first group exercise is provided in traditional way. In second one using GeoGebra applets (three-point bending applet is shown on Figure1). Same test, is given to each group of students. Questions to find the support reactions and the values of bending moment in specific points, as well as to draw the share moment diagrams are included in the test. Results are given in tabl.1.

Table 1. Results from the post test.

\begin{tabular}{|c|c|c|}
\hline Group of 15 students & 1 (traditional) & 2 (GeoGebra) \\
\hline Mean result [\%] & 40 & 65.3 \\
\cline { 2 - 3 }$t$ - value, $p$-value & $t=2.21084$ & $p=0.035<0.05$ \\
\hline Students with 0\% result [\%] & 20 & 0 \\
\hline Students with 100\% result [\%] & 0 & 30 \\
\hline
\end{tabular}

To prove that the mean result of second group differs significantly statistical t-test is used. Results show that with a level of significance $95 \%$ mean results are significantly different. Also, it can be mentioned that $20 \%$ of students from the first group have zero score and there is no maximal score, while in the second group $30 \%$ of the student are with maximal score and no one with zero score. Similar test methodology to prove the positive effect of GeoGebra in Mathematic classes is shown in [15].

\section{Conclusion}

With a help of GeoGebra teachers can easily add the dynamic content in their lectures, which helps students to "feel" the explained physical phenomena and improve their knowledge's in traditionally hard mechanics courses. The GeoGebra applications can also be added as dynamic HTML worksheets to electronic course materials for home preparation. The work of the authors in this field continues not only with developing a new application and virtual 
laboratory experiments but with intensive application in seminary and laboratory classes. Our experiment with comparison of the test results of two group of students shows that group trained with GeoGebra applets have significantly higher mean result.

Our work, just like the work of many GeoGebra users, contributes to its development, which will eventually result in a rich fund of GeoGebra virtual tools, examples and experiences, available worldwide.

\section{References}

1. M. Hohenwarter and K. Fuchs. Computer Algebra Systems and Dynamic Geometry Systems in Mathematics Teaching Conference (2004)

2. J. Hohenwarter, M. Hohenwarter \& Z. Lavicza. Journal of Computers in Mathematics and Science Teaching 28(2), 135-146 (2009)

3. M. Hohenwarter and K. Jones. Proceedings of the British Society for Research into Learning Mathematics 27(3), 126-131 (2007)

4. L. Diković. Computer Science and Information Systems 6.2, 191-203 (2009)

5. M. Hohenwarter and Z. Lavicza. Asian Technology Conference in Mathematics (2010)

6. M. Hohenwarter and Z. Lavicza. Model-Centered Learning (SensePublishers, 7-12, 2011)

7. A. Escuder and J.M. Furner. Retrieved from archives. math. utk. edu/ICTM/vol23/s113/paperpdf(2012)

8. M. Petkova. Proceedings of the Conference History of Mathematics \& Teaching Mathematics, 21-25 May, 2014. Cluj Napoca, Romania (2014)

9. C. Romero and E. Martinez. Proceedings of 4th International Conference on Education and New Learning Technologies (2012)

10. B. Ribeiro and V. Carlos. Creative Education 5.22, 1929 (2014)

11. V. Carbonell, et al. European Journal of Physics 34.4, 991 (2013)

12. V. Milkov, Strength of Materials (theory, problems and software) (In Bulgarian) (TUVarna, 2001)

13. E. Martínez et al. 4th International Conference on Education and New learning Technologies EDULEARN12 Proceedings (2012)

14. X. Iriarte, J. Aginaga, and J. Ros. New Trends in Educational Activity in the Field of Mechanism and Machine Theory (Springer, Cham, 211-219, 2014)

15. L. Diković, Computer Science and Information Systems 6.2, 191-203 (2009) 